\title{
Analisa daya dukung sub das Batang Kumu Kecamatan Rambah Hilir Kabupaten Rokan Hulu
}

\author{
Rudi Hasmadan ${ }^{1}$, Zulkifli ${ }^{2}$, Imam Suprayogi ${ }^{3}$ \\ ${ }^{1,3}$ Pascasarjana Ilmu Lingkungan Program Pascasarjana Universitas Riau \\ ${ }^{2}$ Teknik Sipil Program Pascasarjana Universitas Riau
}

\begin{abstract}
The purpose of the research is to analyze the carrying capacity of Sub watershed Batang Kumu in existing conditions that are useful as a direction for the management of Sub watershed Batang Kumu to maintain sustainability. The method of approach used using policy instruments from the Ministry of Environment and Forestry (LHK) of the Republic of Indonesia which has published regulation of the Minister of Forestry of the Republic of Indonesia no.61 /Menhut II/ 2014 on monitoring and evaluation of watershed management with assessment of criteria covering land, water system, socioeconomic, value of building investment and utilization of regional space. The data used for the research includes land use data, high water level and water quality sample test results sourced from BP-DAS Indragiri Rokan, rainfall data sourced from The River Regional Basin (BWS) of Sumatra III, socioeconomic and population data from the Central Bureau of Statistics (BPS) of Rokan Hulu Regency as well as building investment value data sourced from the Public Work Office of Rokan Hulu Regency. The results of the research stated the total carrying capacity value of Sub watershed Batang Kumu is 117.5. The condition of support capacity of Sub watershed Batang Kumu Sub-District Rambah Hilir Rokan Hulu regency is in the category of bad or in other words Sub watershed Batang Kumu that deserves to maintain its supporting capacity where socioeconomic and institutional assets / value and investment of buildings function as they should. While land conditions, water systems and regional development policies are performance parameters of Sub watershed Batang Kumu which has an influence in increasing the risk of ineligion to the sustainability of watershed ecosystems especially the percentage of critical land, the percentage of vegetation closures and erosion index that shows a very high classification level followed by sub criteria of flooding with high classification and protected areas with very poor classification
\end{abstract}

Keywords: carrying capacity; sub watershed; sustainability

Sub DAS Batang Kumu adalah salah satu sub DAS dari DAS Rokan yang memiliki Daerah Tangkapan Air (DTA) seluas 3.311 ha yang terletak di Kecamatan Rambah Hilir Kabupaten Rokan Hulu. Sub DAS Batang Kumu memiliki salah satu sungai yang berperan strategis serta menjadi andalan dari masyarakat yang berdomisili di bagian hilir untuk kegiatan aktivitas pertanian berupa sawah (irigasi) dan komoditi pertanian lainnya Tiga pilar pembangunan berkelanjutan (ekologi, ekonomi, dan sosialbudaya) menjadikan salah satu bahan pertimbangan pemerintah dalam mengambil kebijakan, terlebih pada obyek vital yang menyangkut hajat hidup orang banyak (BP-DAS Indragiri Rokan, 2015).

Seiring perkembangan waktu maka terjadinya penggunaan lahan akibat masifnya penambahan luasan perkebunan sawit dan aktivitas dari perusahaan Hutan Tanaman Industri (HTI) di bagian Hulu Sub DAS Kumu yang memberi dampak secara signifikan terhadap perubahan siklus hidrologi, khususnya terhadap kondisi tata air di bagian tengah dan hilir dari Sub DAS Batang Kumu dimana area tersebut akan mengalami banjir pada musim hujan dan kekeringan pada saat musim kemarau. Dampak konversi lahan dari hutan sekunder atau semak belukar menjadi lahan perkebunan sawit dan pemanenan tanaman Akasia (Acacia mangium) di bagian hulu Sub DAS Batang Kumu dalam skala besar, dimana kondisi eksisting komposisi tanaman yang sudah membentuk vegetasi dengan kerapatan tajuk yang teratur akan mengalami perubahan struktur pada areal terbuka sehingga berpotensi terjadinya peningkatan degradasi lahan dan percepatan laju aliran permukaan di Sub DAS Batang Kumu.

Fenomena dinamika perubahan suatu DAS yang diilustrasikan di atas, Kementerian Lingkungan Hidup dan Kehutanan (LHK) Republik Indonesia telah menerbitkan Peraturan Menteri Kehutanan Republik Indonesia no.61 /Menhut II/ 2014 tentang monitoring dan evaluasi pengelolaan DAS dengan penilaian kriteria meliputi lahan, tata air, sosial ekonomi, nilai investasi bangunan dan pemanfaatan ruang wilayah tujuannya adalah agar pelaksanaan monitoring dan evaluasi pengelolaan DAS dapat dilakukan secara efektif dan efisien untuk mendapatkan informasi kinerja suatu DAS yang dapat digunakan sebagai dasar perencanaan pengelolaan DAS khususnya Sub DAS Kumu agar tetap berkelanjutan

Selanjutnya Latuihamallo (2017) telah melakukan penelitian di salah satu DAS di Kabupaten Raja Ampat yang harus mendapat perhatian adalah DAS Waisai Dua yang berada tepat di tengah kota Waisai ibukota Kabupaten Raja Ampat. DAS Waisai Dua juga berperan penting dalam menunjang kehidupan masyarakat di kota Waisai yaitu sebagai penyedia air untuk berbagai kebutuhan hidup seperti sumber air 


\section{ZONA}

Jurnal Lingkungan

ISSN : 2502-6496 (Print)

bagi lahan maupun sebagai sumber air bersih bagi masyarakat. Hasil utama penelitian menggunakan instrumen Permenhut Republik Indonesia No 61/Menhut II/2014 menyatakan bahwa kondisi Daya Dukung DAS Waisai Dua Kabupaten Raja Ampat masuk dalam kategori sangat baik atau dengan kata lain DAS Waisai Dua adalah DAS yang dipertahankan daya dukungnya dimana kondisi lahan, kualitas, kuantitas dan kontinuitas air, sosial ekonomi, investasi bangunan air, dan pemanfaatan ruang wilayah berfungsi sebagaimana mestinya. Kondisi soisal ekonomi merupakan parameter kinerja DAS Waisai Dua yang memiliki pengaruh dalam meningkatkan resiko kerawanan terhadap kelestarian ekosistem DAS terutama tekanan penduduk dan tidak adanya penegakan norma. Arahan pengelolaan DAS Waisai Dua saat ini adalah peningkatan kapasitas kelembagaan masyarakat adat dan peningkatan koordinasi dan sinkronisasi antar instansi pemerintah.

Masih dikatakan Latuihamallo (2017) menyarankan kepada Pemerintah Kabupaten Raja Ampat perlu membuat Peraturan Daerah (PERDA) mengenai Pengelolaan DAS Secara Berkelanjutan sehingga kinerja dan daya dukung DAS Waisai Dua tetap dapat dipertahankan dan berfungsi dengan baik. Perlu dilakukan pendampingan dan penyuluhan secara terus menerus kepada masyarakat yang berdomisili di kawasan DAS Waisai Dua tentang pentingnya hutan dalam menjaga tata air dan konservasi tanah di dalam DAS, sehingga masyarakat yang berdomisili di kawasan DAS Waisai Dua terutama petani dan masyarakat adat pemilik hak ulayat dapat memahami dan menjaga DAS Waisai Dua sehingga tetap berfungsi dan memberikan manfaat bagi kehidupan masyarakat.

Selanjutnya Isnan dan Hasnawir (2017) telah melakukan kajian daya dukung DAS Mapili berdasarkan Peraturan Menteri Kehutanan Republik Indonesia Nomor: P.61/Menhut-II/2014 tentang Kriteria Penetapan Klasifikasi Daerah Aliran Sungai, maka DAS Mapili diklasifikasikan menjadi DAS yang dipulihkan daya dukungnya dengan bobot nilai adalah 108,75. DAS Mapili dengan klasifikasi DAS yang dipulihkan daya dukungnya memiliki masalah terutama pada tingkat lahan kritis, tingkat erosi, koefisien rejim aliran, koefisien aliran tahunan, dan indeks penggunaan air. Klasifikasi DAS Mapili sebagai DAS yang dipulihkan daya dukungnya mengidentifikasikan bahwa DAS Mapili memerlukan suatu peningkatan pengelolaan DAS yang lebih baik.

Selanjutnya Sudiana dan Sumantra (2017 telah melakukan kajian dengan melakukan analisis pengelolaan DAS Pekerisan ditinjau dari daya dukung biofisik lahan berdasarkan Peraturan Menteri Kehutanan Republik Indonesia Nomor: P.61/Menhut-II/2014. Hasil penelitian menyatakan bahwa daya dukung DAS Pakerisan adalah kategori baik, hal ini didukung kondisi lahan di DAS Pakerisan tidak diketemukan lahan kritis, penutupan vegetasi dalam kondisi buruk $(31,81 \%)$ karena di DAS Pakerisan merupakan w ilayah budidaya pertanian yang dominan merupakan areal persawahan dan indeks erosi tergolong tinggi (1,37), dikarenakan erosi aktual sebesar 4.119,45 ton/ha/tahun yang terjadi melebihi erosi yang diperkenankan sebesar 3.000 ton/ha/tahun. Kondisi tata air di DAS Pakerisan meliputi koefisien rezim alir an (KRA) tergolong baik (41,57), koefisien aliran tahunan ( K A T) sangat baik $(0,09)$,muatan sedimen sangat tinggi (536 ton/ha/th),kejadian banjir lebih $2 \mathrm{x}$ dalam setahun dengan klasifikasi sangat tinggi dan indeks penggunaan air (IPA) sangat baik $(0,15)$. Pemanfaatan ruang wilayah meliputi kawasan lindung sangat baik (100 \%) dan kawasan budidaya sangat rendah $(100 \%)$.

Merujuk dari keberhasilan penerapan Permenhut Republik untuk melakukan monitoring dan evaluasi sebuah DAS seperti yang dilustrasikan di atas, maka tujuan penelitian adalah melakukan analisis terhadap daya dukung Sub DAS Batang Kumu pada kondisi eksisting yang bermanfaat sebagai arahan untuk pengelolaan Sub DAS Batang Kumu agar tetap keberlanjutan.

\section{METODA PENELITIAN}

\section{Waktu dan Lokasi Penelitian}

Penelitian ini dilaksanakan pada bulan Juni 2019 hingga Desember 2019 di Sub DAS Batang Kumu yang secara administrasi terletak di Desa Pasir Utama, Kecamatan Rambah Hilir, Kabupaten Rokan Hulu. Sub DAS Batang Kumu secara geografis terletak antara $0^{\circ} 56^{\prime} 42,319^{\prime \prime}$ LU dan $100^{\circ} 17^{\prime}$ 52,33 " BT. Diskripsi lokasi penelitian selanjutnya disajikan seperti pada Gambar 1. 


\section{ZONA}

Jurnal Lingkungan

Volume 4, No 2, Oktober 2019, p. 45-50

ISSN : 2502-6496 (Print)

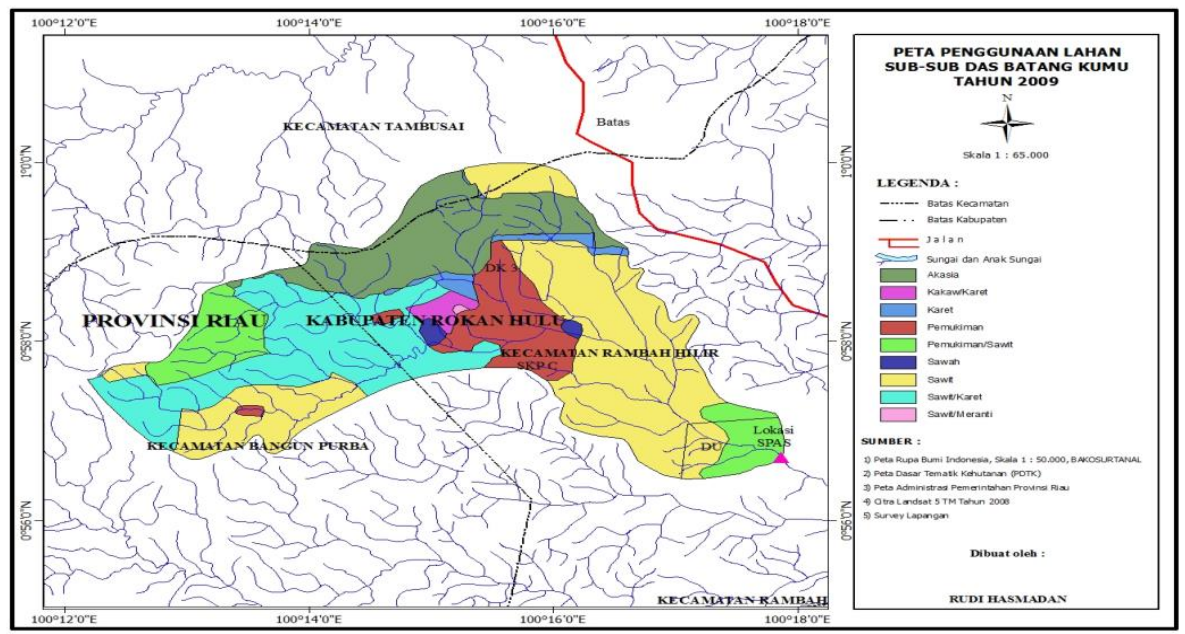

Gambar 1. Lokasi Penelitian

Sumber : BP- DASHL Indragiri Rokan

\section{Alat dan Bahan}

Alat-alat yang digunakan dalam pelaksanaan penelitian keperluan untuk mendukung analisis tata air, penggunaan lahan dan sosial ekonomi di Sub DAS Batang Kumu adalah sebagai berikut : personal computer, plotter dan printer, paket program bantu software Arc View/Arc GIS.

\section{Kebutuhan Data Penelitian}

Data yang dibutuhkan untuk penelitian ini adalah menggunakan data sekunder yang meliputi data penggunaan lahan, data tinggi muka air dan hasil pengujian sampel kualitas air yang bersumber dari BPDAS Indragiri Rokan, data curah hujan bersumber dari Balai Wilayah Sungai (BWS) Sumatera III, data sosial ekonomi dan penduduk dari Badan Pusat Statistik (BPS) Kabupaten Rokan Hulu dan data nilai investasi bangunan bersumber dari Dinas PU Kabupaten Rokan Hulu.

\section{Analisis Data}

Analisa data penelitian berpedoman pada Peraturan Menteri Kehutanan Republik Indonesia Nomor : P. 61 /Menhut-II/2014 Tentang Monitoring dan Evaluasi Pengelolaan Daerah Aliran Sungai yang terdiri dari lima kriteria dan lima belas sub kriteria. Kriteria lahan terdiri dari sub kriteria persentase lahan kritis (PLK), persentase penutupan vegetasi (PPV) dan indeks erosi, diikuti kriteria tata air terdiri dari koefisien rezim aliran (KRA), koefisien aliran tahunan (KAT), muatan sedimen, banjir serta indeks penggunaan air (IPA), kriteria sosial ekonomi dan kelembagaan terdiri dari sub kriteria tekanan penduduk terhadap lahan, tingkat kesejahteraan penduduk dan keberadaan dan penegakan norma. Selanjutnya untuk kriteria asset/ nilai investasi bangunan terdiri dari sub kriteria keberadaan kota dan nilai investasi bangunan air serta kriteria kebijakan pengembangan wilayah terdiri dari sub kriteria kawasan lindung dan kawasan budidaya. Untuk penetapan Klasifikasi Kondisi Daya Dukung DAS (DDD) maka dapat dilihat pada Tabel 2 dibawah ini:

Tabel 2. Klasifikasi Kondisi Daya Dukung DAS (DDD)

\begin{tabular}{lcc}
\hline No & Nilai & Kategori \\
\hline 1. & $\mathrm{DDD} \leq 70$ & Sangat Baik \\
2. & $70<\mathrm{DDD} \leq 90$ & Baik \\
3. & $90<\mathrm{DDD} \leq 110$ & Sedang \\
4. & $110<\mathrm{DDD} \leq 130$ & Buruk \\
5. & $\mathrm{DDD}>130$ & Sangat Buruk \\
\hline
\end{tabular}

Sumber : Permenhut Nomor : P.60/Menhut-II/20

\section{HASIL DAN PEMBAHASAN}

\section{Evaluasi Kinerja dan Daya Dukung DAS}

Berdasarkan hasil skoring masing-masing parameter kinerja DAS, maka kinerja catchment area Sub DAS Batang Kumu adalah sebagaimana tersaji pada Tabel 3. 
Tabel 3. Nilai Daya Dukung Sub DAS Batang Kumu (Eksisting)

\begin{tabular}{|c|c|c|c|c|c|c|c|}
\hline No & $\begin{array}{c}\text { Kriteria/Sub } \\
\text { Kriteria }\end{array}$ & $\begin{array}{l}\text { Bob } \\
\text { ot }\end{array}$ & Nilai & Kelas & $\begin{array}{c}\text { Klasifikas } \\
\mathrm{i}\end{array}$ & Skor & $\begin{array}{l}\text { Hasil } \\
(3 \times 7)\end{array}$ \\
\hline 1 & 2 & 3 & 4 & 5 & 6 & 7 & 8 \\
\hline 1 & Lahan & 40 & & & & & \\
\hline $1 \mathrm{a}$ & $\begin{array}{l}\text { Persentase Lahan } \\
\text { Kritis }\end{array}$ & 20 & $26.35 \%$ & PLK $>20 \%$ & $\begin{array}{l}\text { Sangat } \\
\text { Tinggi }\end{array}$ & 1.50 & 30 \\
\hline $1 \mathrm{~b}$ & $\begin{array}{c}\text { Persentase } \\
\text { Penutupan } \\
\text { Vegetasi }\end{array}$ & 10 & $11.26 \%$ & $\mathrm{PPV}<20 \%$ & $\begin{array}{l}\text { Sangat } \\
\text { Tinggi }\end{array}$ & 1.50 & 15 \\
\hline $1 \mathrm{c}$ & Indeks Erosi & 10 & 2.22 & $\mathrm{IE}>2$ & $\begin{array}{l}\text { Sangat } \\
\text { Tinggi }\end{array}$ & 1.50 & 15 \\
\hline 2 & Tata Air & 20 & & & & & \\
\hline $2 \mathrm{a}$ & $\begin{array}{l}\text { Koefisien Rezim } \\
\text { Aliran }\end{array}$ & 5 & 7.209 & $5<\mathrm{KRA}<20$ & Rendah & 0.75 & 3.85 \\
\hline $2 b$ & $\begin{array}{l}\text { Koefisien Aliran } \\
\text { Tahunan }\end{array}$ & 5 & 0.289 & $\begin{array}{c}0.2<\mathrm{KAT}<0 . \\
3\end{array}$ & Rendah & 0.75 & 3.85 \\
\hline $2 c$ & Muatan Sedimen & 4 & $\begin{array}{c}0.986 \\
\text { t/ha/tahun }\end{array}$ & $<5$ & $\begin{array}{l}\text { Sangat } \\
\text { Rendah }\end{array}$ & 0.50 & 2.0 \\
\hline $2 d$ & Banjir & 2 & 1 kali & 1 kali /tahun & Tinggi & 1.25 & 2.5 \\
\hline $2 \mathrm{e}$ & $\begin{array}{c}\text { Indeks Penggunaan } \\
\text { Air }\end{array}$ & 4 & 0.20 & IPA $<0.25$ & $\begin{array}{l}\text { Sangat } \\
\text { Rendah }\end{array}$ & 0.50 & 2.0 \\
\hline 3 & $\begin{array}{c}\text { Sosial Ekonomi } \\
\text { dan } \\
\text { Kelembagaan }\end{array}$ & 20 & & & & & \\
\hline $3 a$ & $\begin{array}{c}\text { Tekanan } \\
\text { Penduduk } \\
\text { Terhadap Lahan }\end{array}$ & 10 & $0.76 \mathrm{ha} / \mathrm{KK}$ & $0.5<\mathrm{IKL}<1$ & Rendah & 1.25 & 12.50 \\
\hline $3 b$ & $\begin{array}{l}\text { Tingkat } \\
\text { Kesejahteraan } \\
\text { Penduduk }\end{array}$ & 7 & $7.5 \%$ & $5<\mathrm{TKP}<10$ & Baik & 0.75 & 5.30 \\
\hline $3 c$ & $\begin{array}{l}\text { Keberadaan dan } \\
\text { Penegakan Norma }\end{array}$ & 3 & $\begin{array}{l}\text { Ada norma } \\
\text { tidak di } \\
\text { praktekkan }\end{array}$ & 3 & Baik & 0.75 & 2.25 \\
\hline 4 & $\begin{array}{c}\text { Asset/ Nilai } \\
\text { Investasi Bangunan }\end{array}$ & 10 & & & & & \\
\hline $4 a$ & Keberadaan Kota & 5 & $\begin{array}{l}\text { Kota } \\
\text { Sedang }\end{array}$ & $\begin{array}{l}\text { Kelas } \\
\text { Sedang }\end{array}$ & Sedang & 1.00 & 5 \\
\hline $4 b$ & $\begin{array}{l}\text { Nilai Investasi } \\
\text { Bangunan Air }\end{array}$ & 5 & $\begin{array}{l}\mathrm{Rp} 14.75 \\
\text { milyar }\end{array}$ & $\begin{array}{l}\text { IBA }<15 \\
\text { milyar }\end{array}$ & $\begin{array}{l}\text { Sangat } \\
\text { Rendah }\end{array}$ & 0.75 & 3.75 \\
\hline 5 & $\begin{array}{l}\text { Kebijakan } \\
\text { Pengembangan } \\
\text { Wilayah }\end{array}$ & 10 & & & & & \\
\hline $5 a$ & Kawasan Lindung & 5 & $8.2 \%$ & LKL $<15 \%$ & $\begin{array}{l}\text { Sangat } \\
\text { Buruk }\end{array}$ & 1.25 & 6.25 \\
\hline $5 b$ & Kawasan Budidaya & 5 & $86.7 \%$ & $\mathrm{LKB}>70 \%$ & $\begin{array}{l}\text { Sangat } \\
\text { Rendah }\end{array}$ & 0.50 & 2.5 \\
\hline & Total & & & & & & 117.5 \\
\hline
\end{tabular}

Sumber : Hasil Analisis

Merujuk dari Tabel 1 di atas bahwa total nilai daya dukung Sub DAS sebagaimana tersaji pada Tabel $1 \mathrm{di}$ atas adalah sebesar 117.5. Dengan demikian maka dapat disimpulkan bahwa kondisi daya dukung Sub DAS Batang Kumu Kecamatan Rambah Hilir Kabupaten Rokan Hulu masuk dalam kategori buruk. Atau dengan kata lain Sub DAS Batang Kumu adalah Sub DAS yang harus ditingkatkan daya dukungnya.

\section{Arahan Pengelolaan Sub DAS Batang Kumu}

Hasil identifikasi nilai evaluasi daya dukung Sub DAS Batang Kumu Kecamatan Rambah Hilir Kabupaten Rokan Hulu untuk masing- masing kriteria dan sub kriteria sebagaimana yang disajikan pada Tabel 1 menunjukan masalah utama yang ada pada Sub DAS Batang Kumu adalah kriteria lahan dengan sub kriteria : persentase lahan kritis, persentase penutupan vegetasi dan indeks erosi yang menunjukkan tingkat klasifikasi yang sangat tinggi, diikuti kriteria tata air dengan sub 
kriteria banjir dengan kualifikasi tinggi serta kriteria Kebijakan Pengembangan Wilayah dengan sub kriteria kawasan lindung dengan klasifikasi sangat buruk pada Sub DAS Batang Kumu yang merupakan faktor masalah yang harus dicari jawabannya untuk diperbaiki dan ditindaklanjuti, yaitu melalui penyempurnaan perencanaan dan perbaikan pelaksanaan pengelolaan DAS.

Adapun upaya untuk mempertahankan kinerja dan daya dukung Sub DAS Batang Kumu berdasarkan urutan skala prioritas adalah sebagai berikut:

a) Rehabilitasi lahan kritis dengan tindakan vegetatip

Rehabilitasi lahan kritis dengan tindakan vegetatip yang didukung kebijakan dari Provinsi Riau dan Kabupaten Rokan Hulu melalui paket program Rehabilitasi Hutan dan Lahan (RHL) yang sesuai dengan karakteristik biofisik dan sosial ekonomi masyarakat dengan melakukan rehabilitasi hutan dan lahan di area Sub DAS Batang Kumu serta sepanjang alur Sungai Rokan didukung oleh kegiatan gerakan penanaman pada lahan kritis di Sub DAS Batang Kumu.

b) Larangan Konversi Lahan Produktif, Kawasan Hutan Lindung dan Daerah Resapan Air

Larangan konversi lahan produktif, kawasan lindung dan DTA melalui penguatan regulasi Peraturan Daerah Provinsi (PERDA) Provinsi tentang larangan konversi lahan produktif, kawasan lindung dan daerah resapan air melalui program Penyusunan dan Pelaksanaan PERDA Provinsi tentang konversi lahan produktif, kawasan lindung dan daerah resapan air

c) Pemberdayaan Masyarakat dalam Pengelolaan Sub DAS

Pemberdayaan masyarakat dalam pengelolaan Sub DAS Batang Kumu melalui peningkatan peran serta masyarakat dalam pengelolaan Sub DAS Batang Kumu melalui program membangun kemandirian masyarakat dalam pengelolaan Sub DAS Batang Kumu melalui kegiatan dengan kegiatan pelatihan teknis dan pelibatan secara aktif masyarakat pada berbagai program dan pengelolaan Sub DAS Batang Kumu.

\section{d) Penguatan Regulasi Sistem Adaptif Banjir}

Pengendalian banjir melaui penguatan regulasi paket kebijakan sistem adaptif banjir dengan melakukan penyusunan Peraturan Daerah (PERDA) tentang sistem adaptif bencana banjir, PERDA Kabupaten tentang sistem pelayanan minimum bencana banjir melalui kegiatan pemetaaan wilayah rentan banjir, pengembangan sistem deteksi dini banjir, pemetaan sosialisasi dan komunikasi adaptasi banjir, kelembagaan mitigasi bencana di tingkat masyarakat dan pembuatan posko mitigasi banjir di masyarakat

\section{e) Pemantapan Tata Ruang}

Kolaborasi antar pemangku kepentingan sinkronisasi kebijakan tata ruang provinsi dan kabupaten/ kota di wilayah DAS Rokan khususnya Sub DAS Batang Kumu melalui program sinkronisasi tata ruang antara provinsi dan kabupaten / kota dengan prioritas perumusan tata ruang Provinsi yang sinergis implementatip dengan kondisi bioregion Kabupaten/Kota.

\section{KESIMPULAN}

Berdasarkan hasil penelitian maka disimpulkan sebagai berikut :

1. Total nilai daya dukung Sub DAS Batang Kumu adalah sebesar 117.5. Kondisi daya dukung Sub DAS Batang Kumu Kecamatan Rambah Hilir Kabupaten Rokan Hulu masuk dalam kategori buruk. Atau dengan kata lain Sub DAS Batang Kumu yang layak dipertahankan daya dukungnya dimana sosial ekonomi dan kelembagaan asset/ nilai dan investasi bangunan berfungsi sebagaimana mestinya.

2. Kondisi lahan, tata air dan kebijakan pengembangan wilayah merupakan parameter kinerja Sub DAS Batang Kumu yang memiliki pengaruh dalam meningkatkan resiko kerawanan terhadap kelestarian ekosistem DAS terutama persentase lahan kritis, persentase penutupan vegetasi dan indeks erosi yang menunjukkan tingkat klasifikasi yang sangat tinggi diikuti oleh sub kriteria banjir dengan klasifikasi tinggi serta kawasan lindung dengan klasifikasi sangat buruk.

3. Arahan pengelolaan Sub DAS Batang Kumu adalah peningkatan rehabilitasi lahan kritis dengan tindakan vegetatip, larangan konversi lahan produktif, kawasan lindung dan DTA, pemberdayaan masyarakat dalam pengelolaan Sub DAS Batang Kumu, pengendalian banjir melalui penguatan regulasi paket kebijakan sistem adaptif banjir dengan melakukan penyusunan Peraturan Daerah (PERDA) tentang sistem adaptif bencana banjir serta pemantapan tata ruang melalui perumusan tata ruang Provinsi Riau yang sinergis implementatip dengan kondisi bioregion Kabupaten Rokan Hulu. 


\section{DAFTAR PUSTAKA}

Isnan, W dan Hasnawir, 2017. Kajian Daya Dukung Daerah Aliran Sungai (DAS) Mapili Provinsi Sulawesi Barat, Info Teknis Eboni, Vol.14, No.2 Desember 2017, hal 89-102

Latuihamallo, J., Oszaer, R., Putuhena, J., D., 2016. Analisis Kinerja dan Daya Dukung DAS Waisai Dua Kabupaten Raja Ampat Provinsi Papua Barat, Jurnal Hutan Pulau-Pulau Kecil Universitas Pattimura Maluku ,Vol 1, Issue 1, hal 44-52

Kementerian Kehutanan, 2014. Peraturan Menteri Kehutanan Republik Indonesia Nomor : P.61/MenhutII/2014 Tentang Monitoring dan Evaluasi Pengelolaan Daerah Aliran Sungai, Jakarta : Biro Hukum Kementerian Kehutanan Republik Indonesia.

Kementerian Lingkungan Hidup dan Kehutanan (LHK), 2015. Data Primer Monitoring dan Evaluasi Tata Air, Penggunaan Lahan dan Sosial Ekonomi di Sub DAS Batang Kumu Kabupaten Rokan Hulu, Pekanbaru : Balai Pengelolaan DAS dan Hutan Lindung Indragiri Rokan

Sudiani, W dan Sumantra, I., K, 2017. Analisis Pengelolaan Daerah Aliran Sungai Pekerisan Ditinjau Dari Daya Dukung Biofisik Lahan, Prosiding Seminar Nasional Perencanaan Pembangunan Inklusif Desa - Kota, hal 459-467, Padang, 2017. 